\title{
SECAGEM DO CASCALHO DE PERFURAÇÃO VIA AQUECIMENTO POR MICROONDAS
}

\author{
J. M. SANTOS ${ }^{1}$, I. J. PETRI ${ }^{1}$, M. M. R. PENA ${ }^{1}$, C. H. ATAÍDE ${ }^{1}$ \\ ${ }^{1}$ Universidade Federal de Uberlândia, Faculdade de Engenharia Química \\ E-mail para contato: chataide@ufu.br
}

\begin{abstract}
RESUMO - Como efluente da exploração de petróleo há a geração de cascalhos contaminados com fluido de perfuração. A legislação ambiental, quanto ao descarte deste cascalho e a necessidade de reduzir os custos de perfuração, apontam para a necessidade de otimização da separação e reciclagem do fluido de perfuração. A técnica de secagem por microondas foi identificada como uma alternativa para promover essa separação sólidolíquido, na qual os componentes do material são aquecidos individualmente e de forma instantânea. Este trabalho teve como objetivo investigar o efeito do tempo de aquecimento, temperatura e adição de gás de arraste na remoção da fase não aquosa do cascalho contaminado, bem como avaliar a qualidade da n-parafina recuperada no processo via cromatografia gasosa. Os ensaios mostraram que o cascalho submetido à secagem por microondas alcança teores de n-parafina residual que se enquadram na legislação ambiental e que adição do gás aumentou a eficiência do processo de 75 para $90 \%$.
\end{abstract}

\section{INTRODUÇÃO}

Como efluente das operações de exploração de petróleo e gás há a geração de cascalhos contaminados ou revestidos com fluido de perfuração. Esta mistura que retorna a superfície deve ser submetida a processos de separação sólido-líquido de modo que o fluido recuperado possa ser injetado novamente ao poço (SANTOS, 2014). Equipamentos como peneiras vibratórias, centrífugas decantadoras e hidrociclones são responsáveis por promover esta recuperação de fluido e constituem o chamado sistema de controle de sólidos.

Embora este sistema seja capaz de recuperar grande parte do fluido aderido aos sólidos, ele não é capaz de adequar o teor residual orgânico dos cascalhos à legislação ambiental de descarte de resíduos de perfuração, que estabelece que o teor orgânico de fluido sintético aderido aos cascalhos descartados em plataformas offshore não pode ultrapassar 6,9\% em massa (UNITED STATES ENVIRONMENTAL PROTECTION AGENCY, 2010). Com o objetivo de alcançar este parâmetro, foi introduzido ao final do sistema de controle de sólidos o "secador" de cascalho, que na verdade é uma centrifuga filtrante vertical (PETROBRAS, 2011).

Porém, riscos operacionais ligados a esse equipamento e o fato do teor de fluido de perfuração residual alcançado estar muito próximo do limite ambiental, levam a busca por tecnologias alternativas. Com isso, observa-se um crescente interesse em reduzir o teor da fase 


\section{9 a 22 de outubro de 2014 \\ Florianópolis/SC}

orgânica do cascalho proveniente da perfuração de poços, empregando outros equipamentos (PEREIRA, 2013).

A secagem industrial por microondas vem sendo desenvolvida ao longo dos últimos anos e se mostra uma alternativa inovadora para a descontaminação de cascalhos de perfuração. Nesta técnica os hidrocarbonetos não são aquecidos diretamente por serem essencialmente transparentes em frequências de microondas, enquanto que a água presente nos poros e na superfície dos sólidos de perfuração é aquecida e convertida em vapor, este escapa fisicamente dos sólidos e arrasta os hidrocarbonetos. Dessa forma economias significativas de energia são alcançadas por não ser necessário aquecer todo o material (ROBINSON, 2010).

Os resultados obtidos até o momento mostram que os níveis de descontaminação alcançados pelo secador microondas são significativamente superiores aos alcançados em uma centrífuga filtrante. Além disso, o fluido recuperado através dessa técnica se encontra isento de sólidos, ao contrário do que ocorre no processo convencional (PEREIRA, 2013).

Portanto este trabalho tem como objetivo estudar uma nova tecnologia de secagem de cascalhos de perfuração que seja mais eficiente e segura e verificar como o tempo de aquecimento, a temperatura de controle e a injeção de gás de arraste influenciam na remoção da fase orgânica do cascalho contaminado via aquecimento por microondas.

\section{MATERIAL E MÉTODOS}

Os materiais empregados no presente estudo consistem em cascalho seco e fluido de perfuração sintético a base de n-parafina provenientes da central de cascalho da Petrobras, situada no município de Carmópolis - SE.

O método de retorta foi aplicado para medir o teor de n-parafina e água no cascalho, antes e após a secagem. Para isso, foi utilizada retorta Fann de $50 \mathrm{~mL}$. Esse procedimento consiste basicamente em aquecer certa quantidade de cascalho contaminado até que todo fluido seja evaporado. Os vapores são condensados em uma proveta e a concentração foi determinada segundo o procedimento recomendado pelo American Petroleum Institute (2005).

A unidade experimental está ilustrada na Figura 1, e é composta pela cavidade do forno (1) de dimensões $100 \times 60 \times 35 \mathrm{~cm}$ (C x L x A) equipada com 6 fontes de microondas com capacidade individual de $1 \mathrm{~kW}$ (2), operando a $2,45 \mathrm{GHz}$, e conta com balança (3) com capacidade de $600 \mathrm{~kg}$ e precisão de $0,05 \mathrm{~kg}$, banho termostatizado (4), condensador (5), sistema de exaustão (6), painel de controle (7), sistema de aquisição de dados (8), sensor de temperatura (9), transdutor de pressão (10) e injeção de gás de arraste (11).

O controle de temperatura do processo foi realizado em função da temperatura do vapor no interior da cavidade, e corresponde a um controlador do tipo on - off. Quando a temperatura atinge determinados percentuais do valor de set point, as fontes são desligadas e religadas pelo sistema. 


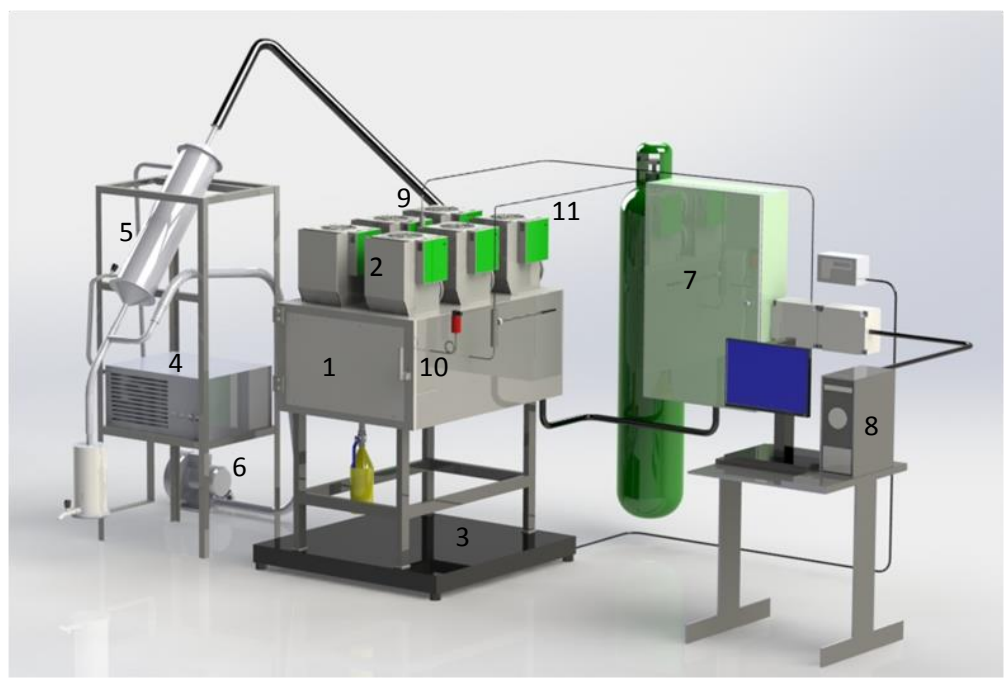

Figura 1 - Unidade Experimental

\subsection{Cinética de Secagem}

Para avaliar a cinética de secagem do cascalho de perfuração por microondas, seis ensaios foram realizados com diferentes tempos de secagem: 24, 36, 45, 60, 72 e 85 minutos de aquecimento. Nestes experimentos, a mistura de cascalho seco e fluido de perfuração resultou em um material com $20 \%$ em massa de fluido, sendo 10,5\% de n-parafina e 9,5\% de água. Além da composição da alimentação, foram mantidas constantes as seguintes propriedades: potência (6 $\mathrm{kW})$, massa $(9 \mathrm{~kg})$ e temperatura de controle dos vapores $\left(120^{\circ} \mathrm{C}\right)$. Como resposta obteve-se o teor residual de n-parafina (\%). O modelo cinético de Page (Equação 1) foi utilizado para descrever a remoção de n-parafina.

$$
x=\exp \left(-k t^{n}\right)
$$

Em que $x$ é a razão de n-parafina $(R N)$, t é o tempo de aquecimento, $k$ e $n$ são parâmetros do modelo em que $k$ representa a taxa de secagem. Neste caso, a razão n-parafina (RN) é expressa pela equação 2:

$$
R N=\frac{Y-Y_{E}}{Y_{0}-Y_{E}}
$$

Onde $Y$ é o teor residual de n-parafina, $Y_{O}$ é o teor inicial de n-parafina e $Y_{E}$ é o teor de equilíbrio de n-parafina. O teor de equilíbrio n-parafina $\left(Y_{E}\right)$ foi assumido como sendo de $1 \%$.

Depois de calcular a razão n-parafina $(R N)$ usando os dados de secagem, os parâmetros do modelo foram determinados através de análise estatística via regressão não-linear da razão de nparafina em função do tempo de secagem. Este modelo foi adotado com base na literatura (PILLAI, 2013; TAHMASEBI et al, 2013), que mostraram bons resultados ao ajustar o modelo de Page na secagem de diferentes produtos via microondas. 


\section{9 a 22 de outubro de 2014 \\ Florianópolis/SC}

\subsection{Efeito da temperatura de controle}

Em cada um dos ensaios, que visaram avaliar a influência da temperatura de controle na descontaminação do cascalho de perfuração, utilizou-se $3 \mathrm{~kg}$ de cascalho contaminado com $11,5 \%$ de n-parafina e $8,5 \%$ de água, $2 \mathrm{~kW}$ de potência e energia específica igual a $0,7 \mathrm{kWh} / \mathrm{kg}$. Já a temperatura dos vapores, variável manipulada nestes ensaios, assumiu os seguintes patamares: 100,110 e $120{ }^{\circ} \mathrm{C}$. Realizou-se três réplicas para cada temperatura adotada e as variáveis resposta foram: teor residual de n-parafina e de água e percentual de remoção de fluido.

Além de avaliar o efeito da temperatura dos vapores na limpeza do cascalho, investigouse também a influencia desta na qualidade da n-parafina recuperada. Essa análise foi feita através de cromatografia gasosa. Para isso, foi utilizado um cromatógrafo gasoso acoplado a um espectrômetro de massa, modelo CGMS - QP2010 Plus da Shimadzu®. As amostras analisadas correspondem a n-parafina recuperada em todos os ensaios apresentados. Os cromatogramas obtidos foram comparados com o cromatogramas da n-parafina pura utilizada na formulação do fluido.

O método utilizado nestas análises cromatográficas consiste de: coluna capilar modelo Rxi - 1ms, injeção de $0,2 \mu \mathrm{L}$, temperatura de injeção igual a $300{ }^{\circ} \mathrm{C}$, temperatura do detector igual a $250{ }^{\circ} \mathrm{C}$, temperatura da fonte de íons igual a $250{ }^{\circ} \mathrm{C}$ e curva de aquecimento de 40 a 250 ${ }^{\circ} \mathrm{C}$ a $10^{\circ} \mathrm{C} / \mathrm{min}$.

\subsection{Efeito da injeção de gás de arraste}

O fluido removido do sistema na fase vapor deve ser recuperado e condensado para que seja reutilizado. Na unidade experimental apresentada, isso é feito através de um sistema de exaustão e condensação. Neste trabalho, foram avaliadas as mudanças que a injeção de um gás inerte provoca no sistema. Para isso, utilizou-se como gás de arraste nitrogênio $\left(\mathrm{N}_{2}\right)$ com $99 \%$ de pureza. Foram realizados ensaios com diferentes vazões de $\mathrm{N}_{2}: 0,15,30,45$ e 60 litros $/ \mathrm{min}$. As demais variáveis foram mantidas constantes: teor inicial de fluido $(20 \%)$, massa $(6 \mathrm{~kg})$, potência aplicada $(6 \mathrm{~kW})$, tempo de aquecimento $(42 \mathrm{~min})$ e temperatura de controle $\left(120^{\circ} \mathrm{C}\right)$. As respostas avaliadas foram: teor residual de n-parafina (\%) e remoção de fluido e de n-parafina (\%).

\section{RESULTADOS E DISCUSSÃO}

\subsection{Cinética de Secagem}

A Figura 2 mostra a variação do teor residual de n-parafina (a) com o tempo de secagem. Como esperado, quanto maior o tempo de secagem, melhor é a remoção de fluido de perfuração. O comportamento observado está de acordo com o apresentado por Pereira (2013). A partir desses dados, determinou-se a razão de n-parafina $(R N)$ e o ajuste não linear desses dados segundo o modelo de Page. Os resultados estão apresentados na Figura 2 (b). O coeficiente de determinação do ajuste é de 0,9983 . 


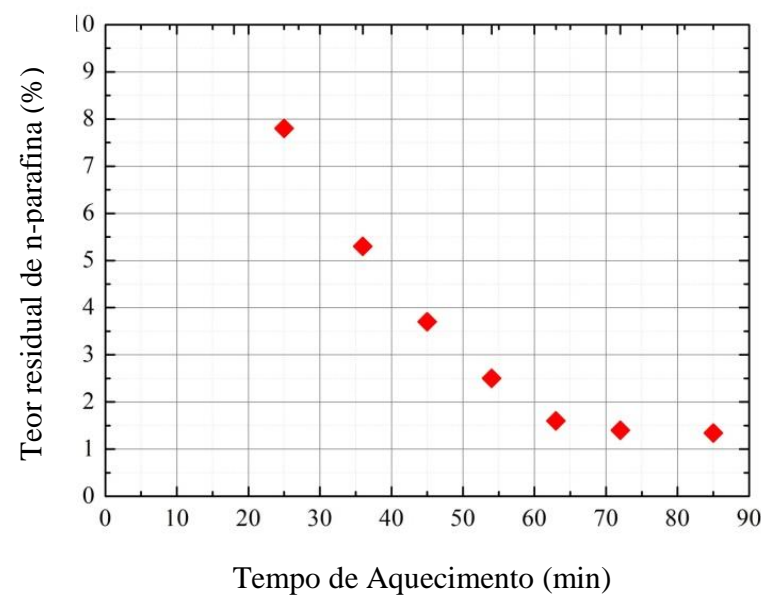

(a)

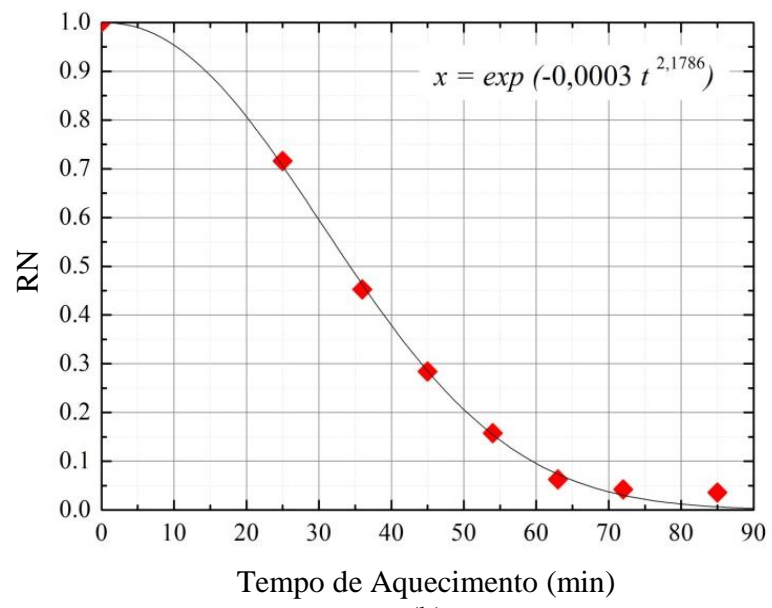

(b)

Figura 2 - Cinética de secagem do cascalho de perfuração por microondas: teor residual de nparafina (a) e ajuste do modelo cinético de Page para razão de n-parafina (b).

Analisando a Figura 2, tem-se que o teor residual de n-parafina decai até atingir o patamar de $1 \%$, quando se torna praticamente estável. Nota-se também, nas condições estudadas, que a partir de 30 minutos de aquecimento o teor residual de n-parafina nos sólidos de perfuração já se encontra abaixo de 6,9\%, atualmente o teor legal permitido para descarte deste resíduo.

Desta forma é possível ajustar o tempo de operação ao objetivo específico de cada ensaio de secagem, ou seja, se o objetivo é adequar o cascalho de perfuração para ser descartado ao ambiente segundo as leis vigentes, este ajuste será realizado de forma que gastos desnecessários de energia sejam reduzidos.

\subsection{Efeito da temperatura de controle}

Ao se avaliar o efeito da temperatura dos vapores gerados durante os ensaios de secagem, foram realizados testes em três temperaturas de controle, 100, 110 e $120{ }^{\circ} \mathrm{C}$. Para tal, foram utilizados os seguintes parâmetros para comparação: percentuais de remoção de fase orgânica e teor residual de água e n-parafina.

Tabela 1 - Valor médio e desvio padrão das respostas obtidas em diferentes temperaturas de controle.

\begin{tabular}{cccccc}
\hline Variáveis $(\mathbf{\%})$ & $\mathbf{1 0 0}^{\circ} \mathbf{C}$ & $\mathbf{1 1 0}^{\circ} \mathbf{C}$ & $\mathbf{1 2 0}^{\circ} \mathbf{C}$ & Média & Desvio Padrão \\
\hline $\begin{array}{c}\text { Teor residual de n- } \\
\text { parafina }\end{array}$ & 2,74 & 2,59 & 2,51 & $\mathbf{2 , 6 1}$ & $\mathbf{0 , 1 2}$ \\
$\begin{array}{c}\text { Teor residual de água } \\
\text { Remoção de n-parafina }\end{array}$ & 1,45 & 1,53 & 1,24 & $\mathbf{1 , 4 1}$ & $\mathbf{0 , 1 5}$ \\
\hline
\end{tabular}


A Tabela 1 mostra a média e o desvio padrão das respostas obtidas nos ensaios que visaram avaliar a influência da temperatura de controle na limpeza do cascalho de perfuração. Observando os valores referentes ao desvio padrão de cada variável resposta obtidos nos testes, foi possível afirmar que, para a faixa de temperatura estudada, a temperatura de controle não afetou significativamente o processo, uma vez que tais valores foram baixos e podem estar ligados aos desvios gerados pelos próprios métodos de análise.

Porém, observou-se que a temperatura de controle afetou o tempo total do processo. Quanto menor o valor do set point, maior foi o tempo total gasto na secagem. O teste realizado a $100{ }^{\circ} \mathrm{C}$ teve duração total de 85 minutos, já o teste realizado a $120{ }^{\circ} \mathrm{C}$ foi finalizado em apenas 70 minutos. Isto ocorre porque menores temperaturas de controle são rapidamente atingidas e mais tempo é gasto no período de controle, em que as fontes são desligadas e religadas.

Para se verificar possíveis alterações na composição da n-parafina devido ao aumento na temperatura dos vapores, foram realizadas análises via cromatografia gasosa acoplada a um espectrômetro de massas. Amostras da fase orgânica do líquido recuperado de testes realizados a 100, 110 e $120{ }^{\circ} \mathrm{C}$, bem como uma amostra da n-parafina extraída do fluido de perfuração, utilizado como contaminante, foram analisadas.

A Figura 3 apresenta os cromatogramas da n-parafina presente no fluido de perfuração e da fase orgânica recuperada nos ensaios de secagem. Observa-se que os principais componentes da n-parafina são hidrocarbonetos de cadeia lineares, contendo de 12 a 16 carbonos. Nota-se também que o aquecimento por microondas não alterou de forma significativa a composição da fase orgânica presente no fluido de perfuração. Os picos dos mesmos componentes foram observados em todos os cromatogramas e apresentaram intensidades relativas (I. R.) semelhantes.
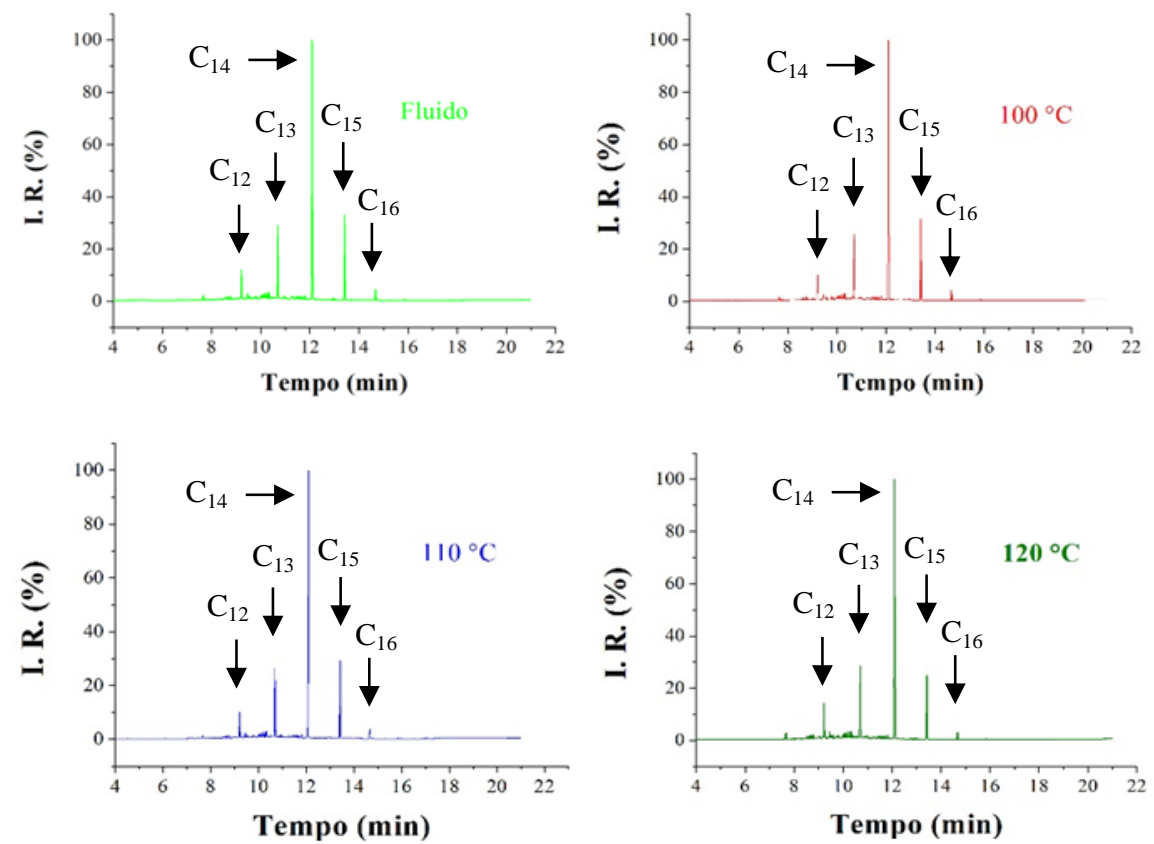

Figura 3 - Cromatogramas da n-parafina presente no fluido de perfuração e da fase orgânica recuperada de ensaios a diferentes temperaturas de controle. 
De acordo com a análise cromatográfica, dentro da faixa estudada, a temperatura dos vapores não influenciou na descontaminação dos cascalhos de perfuração nem na qualidade da nparafina recuperada. Desta forma, a escolha da melhor faixa de temperatura para o processo deverá ser realizada levando-se em conta parâmetros como a carga total de resíduo a ser tratada, tempo disponível e gasto energético.

\subsection{Efeito da injeção de gás de arraste}

A Tabela 2 traz as respostas obtidas nos ensaios realizados a fim de verificar a influência da adição de gás de arraste no interior da cavidade do forno. Foram executados testes de secagem tanto na ausência quanto na presença do gás, utilizando diferentes vazões de alimentação: 15, 30, 45 e 60 litros de nitrogênio gasoso por minuto.

Tabela 2 - Efeito da adição de gás de arraste na descontaminação do cascalho de perfuração.

\begin{tabular}{ccccc}
\hline $\begin{array}{c}\text { Vazão de } \mathbf{N}_{\mathbf{2}} \\
\text { (litros/min) }\end{array}$ & $\begin{array}{c}\text { N-parafina } \\
\text { residual }(\boldsymbol{\%})\end{array}$ & $\begin{array}{c}\text { Água residual } \\
(\boldsymbol{\%})\end{array}$ & $\begin{array}{c}\text { Remoção de n- } \\
\text { parafina }(\boldsymbol{\%})\end{array}$ & $\begin{array}{c}\text { Remoção de } \\
\text { fluido }(\boldsymbol{\%})\end{array}$ \\
\hline $\mathbf{0}$ & 2,82 & 1,81 & 75,46 & 75,81 \\
$\mathbf{1 5}$ & 0,95 & 1,15 & 91,70 & 89,50 \\
$\mathbf{3 0}$ & 1,01 & 1,21 & 91,23 & 88,91 \\
$\mathbf{4 5}$ & 1,17 & 1,56 & 89,81 & 86,33 \\
$\mathbf{6 0}$ & 1,22 & 1,88 & 89,42 & 84,79 \\
\hline
\end{tabular}

Os resultados mostram um aumento de eficiência, ou seja, maior remoção de n-parafina, quando nitrogênio é empregado como gás de arraste. $O$ aumento observado é de aproximadamente 15 pontos percentuais, nas condições operacionais aplicadas. Por outro lado, observa-se que esse aumento de remoção de fase orgânica é independente da vazão de alimentação. Pois, o desvio padrão observado nos resultados entre as diferentes vazões é pequeno e deve estar relacionado, sobretudo, ao método aplicado na medição desses valores.

A presença do gás resfria o ambiente, proporcionando ao material um aquecimento mais gradual. Resultados apresentados por Robinson et al. (2010) e Pereira (2013) mostraram que menores taxas de aquecimento são responsáveis por maiores níveis de remoção da fase orgânica. Isto pode ser explicado pelo fato de que em um aquecimento lento, a água livre permanece mais tempo em contato com a n-parafina e, portanto, a suposta transferência de energia de um material para o outro é maior, favorecendo assim, a retirada da fase orgânica agregada aos sólidos de perfuração.

\section{CONCLUSÕES}

De acordo com os resultados obtidos nos ensaios de secagem e apresentados neste trabalho, nas condições estudadas, foi possível obter as seguintes conclusões: 
$\checkmark$ O cascalho submetido à secagem por microondas alcança teores de n-parafina residual que se enquadram na legislação ambiental e inferiores aos alcançados pela tecnologia atualmente utilizada.

$\checkmark$ A introdução do gás de arraste ao forno, não só tornou a operação do equipamento mais segura, como também aumentou a eficiência do processo de descontaminação dos cascalhos de perfuração. Porém alterações na vazão do gás de arraste não afetaram significativamente na remoção da fase orgânica aderida aos sólidos de perfuração.

$\checkmark$ A composição da n-parafina não é alterada pelo aquecimento por microondas, podendo assim, ser reutilizada na formulação de novos fluidos de perfuração.

\section{REFERÊNCIAS BIBLIOGRÁFICAS}

AMERICAN PETROLEUM INSTITUTE. Recommended Practice for Field Testing of Oil-based Drilling Fluids. Recommended Practice 13B-2.Washington, 2005.

PETROBRAS. Manual de Fluidos. 1. ed. Rio de Janeiro, 2011.

PEREIRA, M. S. Aplicação de Secagem por Microondas no tratamento de cascalho de perfuração. Tese (Doutorado) - Universidade Federal de Uberlândia, Uberlândia, 2013.

PILLAI, M.G., Thin layer drying kinetics, characteristics and modeling of plaster of paris, Chem. Eng. Res. Des., p. 1018-1027, 2013.

ROBINSON, J. P., KINGMAN, S. W., SNAPE, C. E., BRADSHAW, S. M., BRADLEY, M. S. A., SHANG, H., BARRANCO, R. Scale-up and design of a continuous microwave treatment system for the processing of oil-contaminated drill cuttings. Chemical Engineering Research and Design, 88 (2), 146-154, 2010.

SANTOS, J. M., Descontaminação de sólidos de perfuração via aquecimento por micro-ondas. Dissertação (Mestrado) - Universidade Federal de Uberlândia, Uberlândia, 2014.

TAHMASEBI, A., Yu, J., Hana, Y., Zhao, H., Bhattacharya, S., A kinetic study of microwave and fluidized-bed drying of a Chinese lignite. Chem. Eng. Res. Des., 2013.

UNITED STATES ENVIRONMENTAL PROTECTION AGENCY. Statistical Analyses Supporting Final Effluent Limitations Guidelines and Standards for Synthetic-Based Drilling Fluids and other Non-Aqueous Drilling Fluids in the Oil and Gas Extraction Point Source Category, 2010.

\section{AGRADECIMENTOS}

Os autores agradecem ao apoio financeiro da CAPES (bolsa se mestrado e doutorado), FAPEMIG (bolsa de Iniciação Científica), PETROBRAS e a Fundação de Amparo à Pesquisa do Estado de Minas Gerais (FAPEMIG) pelos recursos concedidos no Projeto de Participação Coletiva em Eventos Técnicos-Científicos (PCE-00082-14). 